\title{
Anna Paszkiewicz-Jasińska1
}

\section{WALORY KRAJOBRAZOWE I WARTOŚĆ PRZYRODNICZA ZBIOROWISK ŁACKOWYCH OBSZARU NATURA 2000 „OSTOJA NIETOPERZY GÓR SOWICH”}

\begin{abstract}
Streszczenie. W pracy przedstawiono walory krajobrazowe i wartość przyrodniczą zbiorowisk łąkowych położonych w granicach obszaru objętego programem ochrony Natura 2000 „Ostoja Nietoperzy Gór Sowich”. Na podstawie przeprowadzonych badań wyróżniono 6 zbiorowisk roślinnych, które charakteryzowały się dużym bogactwem gatunkowym (od 64 do 109 gatunków w zbiorowisku) i średnimi wartościami wskaźnika różnorodności florystycznej $\left(H^{\prime}=2,1-2,4\right)$. Największą wartością przyrodniczą charakteryzowało się zbiorowisko łąkowe ze związku Polygono-Trtisetion, wyróżniające się w krajobrazie badanego terenu bogactwem kolorów, dzięki obecności w runi 109 gatunków roślin, w tym wielu barwnie kwitnących. Jego wartość przyrodniczą i krajobrazową podnosi obecność gatunków objętych ochroną ścisłą, wśród nich należących do zagrożonych wymarciem i rzadkich. Wszystkie badane zbiorowiska użytków zielonych, położone wśród ciemnozielonych, dominujących w krajobrazie tego obszaru lasów, są jednym z ważniejszych elementów decydujących o jego walorach krajobrazowych.
\end{abstract}

Słowa kluczowe: zbiorowiska łąkowe, wartość przyrodnicza, walory krajobrazowe, Sudety.

\section{WSTEP}

W regionach górskich za względu na specyficzną rzeźbę terenu, dominuje krajobraz, w którym mniej lub bardziej rozległe doliny, o różnym kształcie otaczają zbocza pokryte lasami [5]. W układzie tym użytki zielone o dużym bogactwie gatunkowym większym, niż niżowe [20] stanowią malowniczy element górskiego krajobrazu. Ich walory krajobrazowe zależą nie tylko od ich udziału w runi, ale także od cech osobniczych gatunku, czasu i intensywności kwitnienia, barwy kwiatu, liści i pędów [5, 18, 19]. Obecności gatunków rzadkich i zagrożonych podnosi ich wartość przyrodniczą i krajobrazową [18].

Celem niniejszej pracy było określenie walorów krajobrazowych oraz wartości przyrodniczej zbiorowisk łąkowych położonych w granicach obszaru objętego programem ochrony Natura 2000 „Ostoja Nietoperzy Gór Sowich”. Obszar ten znajduje się w województwie dolnośląskim, w regionie wałbrzyskim i swoim zasięgiem obejmuje

1 Instytut Technologiczno-Przyrodniczy w Falentach, Dolnośląski Ośrodek Badawczy, ul. Gen. Z. Berlinga 7, 51-209 Wrocław, e-mail: a.paszkiewicz@itep.edu.pl; e-mail: paszkiewicz. anna@gmail.com 
większość pasma Gór Sowich, należących według podziału fizyczno-geograficznego Kondrackiego [3] do makroregionu Sudetów Środkowych.

\section{METODYKA BADAŃ}

Badania terenowe przeprowadzono w latach 2009-2012, na łąkach użytkowanych kośnie i kośno-pastwiskowo, położonych na wysokości od 500 do 850 m n.p.m., w obrębie miejscowości: Glinno, Jugowice, Kolce, Nowa Wieś Kłodzka, Rzeczka, Sierpnica oraz Walim. Wykonano 195 zdjęć fitosocjologicznych metodą Braun-Blanqueta [12]. Gatunki roślin oznaczono przy pomocy klucza Rothmalera [14], nazewnictwo podano za Mirkem i in. [10]. Przy klasyfikacji zbiorowisk wykorzystano prace Chytryego [4], Matuszkiewicza [9] i Perzanowskiej i in. [13].

Wartość przyrodniczą wyróżnionych zespołów i zbiorowisk roślinnych oceniono na podstawie bogactwa gatunkowego (liczby gatunków ogółem i średniej liczby gatunków w zdjęciu) oraz wskaźnika różnorodności Shannona-Wienera $H^{\prime}$ [8]. Odnotowano gatunki objęte ochroną całkowita i częściową [15] oraz rzadkie i zagrożone wyginięciem [7]. Przeprowadzono obserwacje dotyczące walorów estetycznych i krajobrazowych badanych łąk oraz notowano terminy występowanie aspektów florystycznych wielu gatunków roślin. Wykonano również bogatą dokumentację fotograficzną w celu zobrazowania walorów wizualnych badanego terenu.

\section{WYNIKI}

Zbiorowiska roślinne użytków zielonych zakwalifikowano do jednej klasy Molinio-Arrhenatheretea. Wyróżniono w sumie 1 zespół Arrhenatheretum elatioris oraz 5 fitocenoz w randze zbiorowiska: Alopecurus pratensis, Poa pratensis-Festuca rubra, Agrostis capillaris, Festuca rubra oraz zbiorowisko związku Polygono-Trisetion (górskie łąki konietlicowe). Poniżej przedstawiono ich fitosocjologiczną klasyfikację w ujęciu systematycznym:

Klasa: Molinio-Arrhenatheretea R. Tx. 1937

Rząd: Molinietalia caeruleae W. Koch 1926

Związek: Caltion palustris R. Tx. 1936 em. Oberd. 1957

Zbiorowisko: Alopecurus pratensis

Rząd: Arrhenatheretalia Pawł. 1928

Związek: Arrhenatherion elatioris (Br.-Bl. 1925) Koch 1926

Zespół: Arrhenatheretum elatioris Br.-Bl. ex Scherr. 1925

Zbiorowisko: Poa pratensis-Festuca rubra Fijałk. 1962 pro ass.

Zbiorowisko: Agrostis capillaris

Zbiorowisko: Festuca rubra

Związek: Polygono-Trisetion Br.-B1. ex Scherr. 1926

Zbiorowisko zw. Polygono-Trisetion 
W krajobrazie badanego terenu najbardziej rozpowszechnione są zbiorowiska łąk świeżych zaklasyfikowane do rzędu Arrhenatheretalia. Występują najczęściej na nasłonecznionych stokach i wierzchowinach wzniesień, w warunkach optymalnie uwilgotnionych gleb lub okresowo przesychających, w sąsiedztwie lasów, rzadziej pól uprawnych. Na niewielkich powierzchniach, w siedliskach okresowo wilgotnych odnotowano zbiorowiska łąk wilgotnych.

\section{Charakterystyka i walory krajobrazowe wyróżnionych zbiorowisk}

Zespół Arrhenatheretum elatioris (łąka rajgrasowa) odnotowano w niższych położeniach, na wysokości od 530 do $590 \mathrm{~m}$ n. p. m., zarówno na powierzchniach płaskich, jak i nachylonych, o różnej ekspozycji. Wyróżniono go na podstawie obecności gatunków charakterystycznych dla tego zespołu: Arrhenatherum elatius i Geranium pratense oraz dla związku Arrhenatherion: Campanula patula, Crepis biennis, Galium mollugo, Knautia arvensis i Tragopogon pratensis. $\mathrm{Z}$ traw najliczniej, prócz Arrhenatherum elatius, odnotowano m.in. Dactylis glomerata, Trisetum flavescens i Festuca rubra, a $\mathrm{z}$ dwuliściennych: Achillea milefolium, Trifolium pratense, Lathyrus pratensis, Lotus corniculatus. Gatunki te nadają zbiorowisku duże walory estetyczne, co przekłada się na ich wartość krajobrazową. Łąki rajgrasowe prezentują się efektownie zarówno wczesną wiosną, jak i w pełni lata. Na tle srebrzystej barwy Arrhenatherum elatius obserwuje się grę kolorów, związaną z kwitnieniem i dojrzewaniem gatunków dwuliściennych. Barwę żółtą nadają wiosną - Taraxacum officinale, latem - Crepis bienis, Leondoton hispidus, Lotus corniculatus, Lathyrus pratensis, białą - Galium mollugo, Leucanthemum vulgare, Achillea millefolium, niebieską - Campanula patula, różowoniebieską - Knautia arvensis, Geranium pratense, a czerwoną - Trifolium pratense.

Zbiorowisko Poa pratensis-Festuca rubra (łąka wiechlinowo-kostrzewowa) występuje na suchych stokach. Wyróżniono je na podstawie dominacji dwóch gatunków - Festuca rubra i Poa pratensis. W zbiorowisku odnotowano duży udział Holcus lanatus, Anthoxanthum odoratum i Agrostis capillaris. Trawy te tworzą zielone tło dla barwnie kwitnących gatunków dwuliściennych: różowo - Thymus pulegioides i Dianthus deltoides, żółto - Leontodon autumnalis oraz biało - Achillea millefolium. Walory krajobrazowe tego zbiorowiska podnoszą także różnorodne kwiatostany budujących je traw.

Zbiorowisko Agrostis capillaris (łąka z mietlicą pospolita) odnotowano na wysokości 520-545 m n.p.m. Wyróżniono je na podstawie dominacji Agrostis capillaris, który podczas kwitnienia nadaje całemu zbiorowisku barwę czerwonofioletową. Zbiorowisko to zajmuje miejsce po zubożałych florystycznie łąkach rajgrasowych [1], o czym świadczy występowanie gatunków właściwych dla zespołu Arrhenatheretum elatioris i związku Arrhenatherion: Arrhenatherum elatius, Campanula patula, Galium mollugo, Knautia arvensis i Tragopogon pratensis. W płatach omawianej fitocenozy odnotowano również gatunki reprezentatywne dla górskich łąk konietlicowych (3, 13), m. in. Trisetum flavescens, Festuca rubra, Dactylis glomerata, Luzula luzulaides, 
Campanula_rotundifolia, Chaerophylum hirsutum, Alchemilla monicolat. Pomimo dominacji traw, dzięki udziałowi w runi gatunków dwuliściennych, łąki z Agrostis capillaris tworzą barwne i kwieciste powierzchnie, co wpływa na ich duże walory krajobrazowe.

Zbiorowisko Festuca rubra (łąka z kostrzewą czerwoną) wystąpiło na stanowiskach położonym na wysokości 530-580 m n.p.m., o wystawie północno i południowo-zachodniej. Zbiorowisko to zostało określone na podstawie dominacji Festuca rubra. Odnotowano gatunki charakterystyczne dla związku Arrhenatherion: Arrhenatherum elatius, Campanula patula, Crepis biennis, Galium mollugo, Knautia arvensis i Tragopogon pratensis oraz dla rzędu Arrhenatheretalia, m. in. Lotus corniculatus, Achillea millefolium, Trisetum flavescens, Leucanthemum vulgare, Heracleum sphondylium, Pimpinella major. Urok zbiorowisku dodają kwitnąca biąło - Trifolium repens, rózowo - Thymus pulegioides oraz żółto - Hieracium pilosella. Duży udział gatunków dwuliściennych nadaje wielobarwności zbiorowisku, w którym odbywa się gra kolorów, zależnie od pory roku.

Zbiorowisko ze związku Polygono-Trisetion (łąka konietlicowa), odnotowano w wyższych położeniach terenu od 600 do 850 m n.p.m., tylko jedno stanowisko zlokalizowane było poniższej $600 \mathrm{~m}$ n.p.m. Zbiorowisko to wyróżniono na podstawie obecności w runi gatunków wymienianych jako reprezentatywne dla górskich łąk konietlicowych użytkowanych ekstensywnie [3, 13], takich jak: Festuca rubra, Alchemilla monticola, Trisetum flavescens, Agrostis capillaris, Campanula rotundifolia, Cirsium helenioides, Chaerophyllum hirsutum, Luzula luzuloides, Gymnadenia conopsea subsp. conopsea, Hypericum maculatum. Obecność taksonów charakterystycznych dla związku Arrhenatherion wskazuje na przejściowy charakter tego zbiorowiska. Liczną grupę stanowią rośliny dwuliścienne rzędu Arrhenatheretalia i z klasy Molinio-Arrhenatheretea. Zbiorowisko to, dzięki dużemu bogactwu gatunkowemu tworzy niezwykle barwne i kwieciste powierzchnie, o wielu wyróżniających się aspektach sezonowych.

Zbiorowisko Alopecurus pratensis odnotowano w miejscach wilgotnych, w pobliżu wysięków. Wyróżniono je na podstawie gatunku dominującego Alopecurus pratensis, który w okresie kłoszenia nadaje zbiorowisku barwę szarą, a podczas kwitnienia rudą. W składzie gatunkowym odnotowano taksony charakterystyczne dla związku Calthion: Caltha palustris, Cirsium oleraceum, Cirsium rivulare, Juncus conglomeratus, Juncus effusus, Myosotis palustris, Scirpus sylvaticus oraz rzędu Molinietalia: Angelica sylvestris, Cirsium palustre, Colchicum autumnale, Deschampsia caespitosa, Lotus uliginosus, Lychnis flos-cuculi Sanguisorba officinalis oraz Trollius europaeus. W zbiorowisku zaznaczył się również duży udział Filipendula ulmaria ze związku Filipendulion. Z gatunków łąkowych wystąpiły między innymi: Lotus corniculatus, Festuca pratensis, Lathyrus pratensis oraz Vicia cracca. Walory krajobrazowe zbiorowiska związane są z wielogatunkową, barwną runią. Zieleń traw wiosną ożywiają kwitnące na żółto - Caltha palustris i Trollius europaeus, nieco później Lotus corniculatus, Lotus uliginosus, Lathyrus 
pratensis, różowo - Lychnis flos-cuculi, niebiesko - Myosotis palustris, późnym latem białe kwiatostany Filipendulia ulmaria, brunatne - Sanguisorba officinalis. Walorów estetycznych dostarczają również licznie występujące okazałe byliny o dużych, pięknych kwiatostanach: Cirsium oleraceum (bladożółtych) oraz Cirsium rivulare (purpurowych).

\section{Wartość przyrodnicza wyróżnionych zbiorowisk}

Zbiorowiska roślinne badanego obszaru charakteryzują się dużym bogactwem gatunkowym oraz średnimi wartościami wskaźnika różnorodności florystycznej. Najwięcej gatunków ogółem wystąpiło w zbiorowisku ze związku Polygono-Trtisetion - 109 oraz w zespole Arrhenatheretum elatioris - 105 gatunków. Zbiorowisko Poa pratensis-Festuca rubra odznaczało się najmniejszą liczbą gatunków ogółem (64 gatunków), natomiast największą średnią liczbą gatunków w zdjęciu fitosocjologicznym.

Wskaźnik różnorodności florystycznej $H^{\prime}$ wyróżnionych zbiorowisk jest mało zróżnicowany, jego wartość waha się od 2,1 do 2,4. Najmniejszą różnorodnością odznacza się zbiorowisko Agrostis capillaris, nieco większą zbiorowisko Festuca rubra. Najwyższą wartością wskaźnika Shanona-Wiernera charakteryzuje się zbiorowisko Poa pratensis-Festuca rubra.

Tabela 1. Bogactwo gatunkowe i różnorodność florystyczna zbiorowisk łąkowych

Table 1. Species richness and floristic diversity of meadow communities

\begin{tabular}{|l|c|c|c|}
\hline \multirow{2}{*}{\begin{tabular}{c}
\multirow{2}{*}{$\begin{array}{c}\text { Zbiorowisko roślinne } \\
\text { Plant community }\end{array}$} \\
\cline { 2 - 3 }
\end{tabular}} & $\begin{array}{c}|c| \\
\text { ogółem } \\
\text { total }\end{array}$ & $\begin{array}{c}\text { Liczba gatunków } \\
\text { średnia w zdjęciu fitoso- } \\
\text { cjologicznym } \\
\text { mean in releve }\end{array}$ & $\begin{array}{c}\text { Wskaźnik różnorodności } \\
\text { florystycznej } H^{\prime} \\
\text { zbiorowiska } \\
\text { Index of floristic diversity } H^{\prime} \\
\text { of the community }\end{array}$ \\
\hline Alopecurus pratensis & 68 & 24,4 & 2,3 \\
\hline Arrhenatheretum elatioris & 105 & 25,8 & 2,3 \\
\hline Poa pratensis-Festuca rubra & 64 & 27,8 & 2,4 \\
\hline Agrostis capilaris & 92 & 23,8 & 2,1 \\
\hline Festuca rubra & 86 & 26,1 & 2,2 \\
\hline zw. Polygono-Trisetion & 109 & 24,8 & 2,3 \\
\hline
\end{tabular}

W wyróżnionych zbiorowiskach odnotowano obecność gatunków objętych ochroną gatunkową ścisłą i częściową. Najwięcej gatunków chronionych odnotowano w fitocenozie związku Polygono-Trisetion - Carlina acaulis, Gymnadenia conopsea subsp. conopsea i Platanthera bifolia. Po dwa gatunki odnotowano w zbiorowiskach: Alopecurus pratensis - Colchicum autumnale i Trollius europaeus oraz Festuca rubra - Carlina acaulis i Primula veris, a jeden w zbiorowisku Poa pratensis-Festuca rubra - Carlina acaulis. Na użytkach zielonych badanego terenu notowano również obecność Iris sibirica, Dactylorhiza majalis, Dactylorhiza maculata i Lilium martagon. 
Większość z wyżej wymienionych gatunków umieszczona jest na listach zagrożonych gatunków flory naczyniowej Dolnego Śląska [7], jako gatunki narażone na wymarcie oraz gatunki o niższym ryzyku wymarcia (rzadkie). Do gatunków narażonych na wymarcie (VU) należą: Trollius europaeus, Iris sibirica, Gymnadenia conopsea subsp. conopsea, Dactylorhiza maculata. Z gatunków o niższym ryzyku wymarcia wystąpiły bliskie zagrożenia (NT): Dactylorhiza majalis i Eriophorum vaginatum $\mathrm{w}$ zbiorowisku z Alopecurus pratensis oraz słabo zagrożone (LC) - Colchicum autumnale i Platanthera bifolia.

\section{DYSKUSJA I PODSUMOWANIE}

Przeprowadzone badania florystyczno-fitosocjologiczne na użytkowanych łąkach znajdujących się w granicach obszaru Natura 2000 „Ostoja Nietoperzy Gór Sowich” pozwoliły na wyróżnienie 6 jednostek fitosocjologicznych, które zakwalifikowano do jednej klasy Molinio-Arrhenatheretea. W wielu regionach naszego kraju zbiorowiska tej klasy należą do najważniejszych formacji roślinnych określających fizjonomię krajobrazu [9]. Stanowią ważny jego składnik również w regionie Sudetów, co potwierdzają badania wielu autorów $[1,2,22,11,23]$.

Różnorodne florystyczne i bogate $\mathrm{w}$ gatunki zbiorowiska roślinne użytków zielonych to jeden z ważniejszych element decydujący o ich walorach krajobrazowych [21, $16,5]$. Wyróżnione na obszarze badań zbiorowiska łąkowe charakteryzują się dość dużym bogactwem gatunkowym (od 64 do 109 gatunków) oraz średnimi wartościami wskaźnika różnorodności florystycznej. Ich wartość przyrodnicza w tym zakresie jest jednak większa od uzyskanej dla tych samych zbiorowisk przez Żyszkowską [22] w dolinie Bystrzycy Dusznickiej w Sudetach Środkowych oraz Żyszkowską i Paszkiewicz-Jasińską [23] na Pogórzu Złotoryjskim.

Obecność cennych roślin rzadkich, zagrożonych i ginących, podnosi wartość przyrodniczą zbiorowisk łąkowych użytków zielonych, a także ich walory krajobrazowe, co podkreśla wielu autorów [18, 20]. Według Szoszkiewicz i Szoszkiewicz [17] to obecność tych gatunków decyduje o wartości przyrodniczej fitocenoz, a nie wartość wskaźnika bioróżnorodności. W badanych zbiorowiskach łąkowych odnotowano gatunki podlegające ochronie ścisłej i częściowej, z których część jest wymieniana jako zagrożone oraz rzadkie na Dolnym Śląsku.

Największą wartością przyrodniczą charakteryzowało się zbiorowisko łąkowe ze związku Polygono-Trtisetion, wyróżniające się w krajobrazie badanego terenu bogactwem kolorów, dzięki obecności 109 gatunków w runi, w tym wielu barwnie kwitnących. Jego wartość przyrodniczą i krajobrazową podnoszą rośliny objęte ochroną ścisłą, wśród nich należących do zagrożonych wymarcie i rzadkich.

Wszystkie badane zbiorowiska łąkowe, rozrzucone wśród cimnozielonych, dominujących w krajobrazie lasów, są jednym z ważniejszych elementów decydujących o walorach krajobrazowych obszaru Natura 2000 „Ostoja Nietoperzy Gór Sowich”. 


\section{PIŚMIENNICTWO}

1. Grynia M., Kryszak A. 1996. Ocena geobotaniczna zbiorowisk łąkowych Obniżenia Dusznickiego oraz Gór Bystrzyckich. Zesz. Probl. Post. Nauk Roln. 442, 97-104.

2. Grynia M., Kryszak A. 1999. Porównanie różnorodności florystycznej zespołów łąkowych najczęściej występujących w Górach Bystrzyckich i Karkonoszach. Pozn. Tow. Przyj. Nauk, Prace Komisji Nauk Rolniczych i Komisji Nauk Leśnych, Prace 87: 20-25.

3. Kondracki J. 2000. Geografia fizyczna Polski. (Physical geography of Poland) Warszawa, Wydaw. Nauk. PWN: ss. 468.

4. Chytrý M. (ed.) 2007. Vegetace České republiky 1. Travinná a keříčková vegetace. Vegetation of the Czech Republic 1. Grassland and Heathland Vegetation. Academia, Praha, ss.525.

5. Fatyga J. 2000. Charakterytstyka i wartość uzytkowa kilku zbiorowisk roślinnych występujących w Sudetach. Wiad. IMUZ, XX, 3: 41-74.

6. Grynia M., Kryszak A. 1996. Ocena geobotaniczna zbiorowisk łąkowych Obniżenia Dusznickiego oraz Gór Bystrzyckich. Zesz. Probl. Post. Nauk Roln. 442, s.97-104.

7. Kącki Z. 2003. Zagrożone gatunki flory naczyniowej Dolnego Śląska 2003. Pr. zbior. red. Z. Kącki, Wrocław: IBRUW, PTPP „Pro Natura”: 245.

8. Krebs Ch. 1997. Ekologia. Eksperymentalna analiza rozmieszczenia i liczebności. Wyd. Nauk. PWN Warszawa. ss.737.

9. Matuszkiewicz W. 2007. Przewodnik do oznaczania zbiorowisk roślinnych Polski. Warszawa, Wydaw. Nauk. PWN: 537.

10. Mirek Z., Piękoś-Mirkowa H., Zając A, Zając M. 2002. Flowering plants and pteridophytes of Poland: A checklist. Kraków, W. Szafer Inst. Bot. Pol. Acad. Sci.: 442.

11. Paszkiewicz-Jasińska A., Żyszkowska M. 2011. Charakterystyka i ocena stopnia synantropizacji zbiorowisk łąkowych Gór Sowich (Sudety Środkowe). Acta Bot. Sil., 7: 37-47.

12. Pawłowski B. 1977. Skład i budowa zbiorowisk roślinnych oraz metody ich badania. [W:] Szafer, K. Zarzycki (red.), Szata roślinna Polski. T. 1. Wyd. Nauk. PWN, Warszawa: 237-268.

13. Perzanowska J., Świerkosz K, Mróz W. 2004. Górskie łąki konietlicowe użytkowane ekstensywnie (Polygono-Trisetion). W: Herbich J. (red.), Murawy, łąki, ziołorośla, wrzosowiska, zarośla. Poradniki ochrony siedlisk i gatunków Natura 2000 - podręcznik metodyczny. Tom 3. - Ministerstwo Środowiska, Warszawa: 212-219.

14. Rothmaler W. 2002.Exkurisionsflora von Deutschland. Gefaspflanzen: Kritischer Band. Band 4, Spektrum AkademischerVerlag, Heidelberg, Berlin, ss. 948.

15. Rozporządzenie MŚ Z dnia 5 stycznia 2012 r. w sprawie ochrony gatunkowej roślin.Dz. U. Dziennik Ustaw z 20 stycznia 2012 poz. 81 http://www.infor.pl/dziennik-ustaw,rok,2012,nr,14/poz,81.html

16. Sabiniarz A., Kozłowski S, 2009. Łąki Czerskie w aspekcie krajobrazowym (Landscape aspects of Czersk Meadows). Poznań, Łąkarstwo w Polsce, 12: 141-155.

17. Szoszkiewicz K., Szoszkiewicz J. 1998. Ocena różnorodności gatunkowej pratacenoz na przykładzie wybranych zbiorowisk. Pozn. Tow. Przyj. Nauk, Wydz. Nauk Rol. i Leśn., 85: 47-51.

18. Trąba Cz. 1999. Florystyczne i krajobrazowe walory łąk w dolinach rzecznych kotliny zamojskiej. Fol. Univ. Agric. Stein. 197 Agricultura (75): 321-324.

19. Trzaskoś M., 1998. Zróżnicowanie składu botanicznego i wartości paszowej runi łąk ziołowych nizinnych i podgórskich. Kraków, Zesz. Nauk. AK 330 Ses. Nauk 54: 75-85.

20. Wolański P., Trąba Cz. 2009. Walory estetyczne i rekreacyjne łąk oraz zbiorowisk przyległych na Pogórzu Dynowskim. Nauka Przyr. Technol., 3, 1, 1-8. 
21. Wyłupek A., Kozłowski S. 2009. Łąki Czerskie w aspekcie krajobrazowym. Poznań, Łąkarstwo w Polsce, 12: 141-155.

22. Żyszkowska M. 2004. Różnorodność gatunkowa użytkowanych i nieużytkowanych łąk w dolinie rzeki górskiej - Bystrzycy Dusznickiej. Woda Środ. Obsz. Wiej. t. 4 z. 2b (12), 161-174.

23. Żyszkowska M., Paszkiewicz-Jasińska A. 2011. An assessment of the natural value of selected meadow-pasture communities in the Middle Sudetes region. Jour. Water Land Dev. 15, 53-64.

\title{
LANDSCAPE AND NATURAL VALUES OF MEADOW COMMUNITIES WITHIN THE NATURA 2000 „OSTOJA NIETOPERZY GÓR SOWICH” AREA
}

\begin{abstract}
The paper presented landscape and natural values of meadows situated within the Natura 2000 "Ostoja Nietoperzy Gór Sowich" area. Based on the study, 6 plant communities were highlighted. They were characterized by high species richness (from 64 to 109 species in a community) and average values of floristic diversity index $H^{\prime}(2.1-2.4)$. The greatest natural value of grassland community was found in Polygono-Trtisetion community - distinctive in its color richness, thanks to the presence in the sward of 109 species of plants, including many colorfully flowering ones. Its natural and landscape value was increased by the presence of species under strict protection (with endangered and rare species among them). All studied grassland communities, located among dark green forests, which dominate in this area, are one the most important element deciding about landscape values.
\end{abstract}

Key words: meadow communities, natural value, landscape values, the Sudetes. 